Revista Iberoamericana. Vol. LXIII, Núm. 181, Octubre-Diciembre 1997; 621-630

\title{
ARGIRÓPOLIS, CANUDOS Y LAS FAVELAS. UN ENSAYO DE LECTURA COMPARADA
}

\author{
POR \\ Miriam GÁrate \\ Universidad de Campinas-Brasil
}

Entre los tópicos actualizados en Facundo para configurar el binomio civilización/ barbarie, otro binomio, indisociable del anterior, el binomio ciudad/campo, desempeña sin duda un papel importantísimo. El motivo persistirá a lo largo de la obra sarmientina y será en parte responsable por la proyección de una urbs utópica: Argirópolis, futura capital de la Confederación Argentina, ciudad "echada en el agua" (Argirópolis 144). Vale la pena señalar, no obstante, que si la idealidad e insularidad de Argirópolis condicen con ciertos rasgos típicos del género, el libro como un todo difícilmente puede ser considerado una utopía. Su espíritu pragmático, al margen de la viabilidad o inviabilidad del proyecto formulado, es demasiado fuerte: Argirópolis quiere ser una real solución para los problemas del país, un efectivo instrumento de equilibrio y reconciliación entre los diversos intereses en pugna. Argirópolis quiere, además y por sobre todo, seducir al único hombre con posibilidades de derrotar a Rosas: don Justo José de Urquiza, gobernador de la provincia de Entre Ríos, provincia que “... el día que haya leyes inteligentes de navegación, será el paraíso terrenal ... el conjunto más compacto de ciudades florecientes" (Argirópolis 141); provincia donde - y esto podría servir de epígrafe a la primera parte de este trabajo- "debería prohibirse la cría de ganado, para entregarse sin estorbo a la cría de ciudades" (Argirópolis 143, énfasis mío). ${ }^{1}$

\footnotetext{
1 Vale la pena recordar algunos datos referentes al marco histórico en el que se inserta el corpus sarmientino a ser analizado. Concluido el ciclo de las luchas independentistas, el territorio argentino ingresa en una fase de prolongados enfrentamientos internos (la así llamada "anarquía de los años veinte") entre sectores partidarios de una organización político-institucional centralizada (unitarios) y grupos aparentemente empeñados en la consolidación de un régimen respetuoso de las autonomías provinciales (federales). En 1829, Sarmiento se alista en las filas del unitarismo: "Me informé de las tendencias y objetos de los partidos, y no me fue difícil escoger el que me convenía. Veía en uno a los viejos retrógrados, a los antiguos godos y a los gauchos ignorantes; en otro a los jóvenes, a los antiguos patriotas y a los que abogaban por la libertad. Nada más necesitaba, fui unitario desde entonces" (Sarmiento, Mi Defensa). Concomitantemente, Juan Manuel de Rosas, importante hacendado de Buenos Aires y jefe de la facción federal, asume por primera vez el gobierno de su provincia, permaneciendo en el cargo hasta 1832 . En 1835, y en un clima no menos caótico, vuelve a ser designado gobernador de Buenos Aires. Investido de la "suma del poder público", Rosas inicia una gestión que sólo será interrumpida en 1852, después de ser derrotado por Urquiza en la batalla de Caseros. Propiciando alianzas con diversos caudillos regionales, preservando las prerrogativas
} 
Sarmiento quiso erguir la urbe sobre el agua una ciudad que no fue pero que representaba la quintaesencia de ciertos valores caros cuya sede era, para el autor y para su época. En Los Sertones, la dos veces sumergida, Canudos/Belo Monte representó la irrupción de lo "inclasificable" al mismo tiempo que dejó entrever algo del orden del porvenir, que hizo de Euclides, o mejor aún de la obra euclidiana vista a través de esta lectura, una suerte de profeta involuntario. Edificada a salvo de miradas intrusas, resguardada por el "monte de la Favela" donde habrían de apostarse las fuerzas del ejército republicano para mejor bombardearla, Canudos no pudo resistir al embate. La sepultaron, es cierto, pero resurgió y se multiplicó en otros sitios, subió laderas y colinas, se hizo "favela". 2

De las varias actualizaciones y versiones del binomio ciudad/campo en la escritura de uno y otro autor trata el presente ensayo.

\section{Materia y propiedades de la URBE}

En Facundo no se define a la civilización pero se la "ubica" y "predica" sin cesar, infatigablemente. Ninguna duda sobre su dirección, la civilización habita en la ciudad,

aduaneras de su provincia de origen y obteniendo importantes concesiones de las provincias del interior (tal como el derecho de representarlas e intermediar por ellas en el comercio externo), Rosas impuso de hecho un modelo centralizado y hegemonizado por los sectores vinculados a la explotación pecuaria, establecidos en Buenos Aires. Durante los casi veinte años en que ejerció el poder fue implacable en el combate a los grupos opositores y, desde esa perspectiva, 1840, año de creación de la Mazorca, señala uno de los momentos más críticos de la vida política argentina del XIX. En ese año y en los inmediatamente posteriores, la "nueva generación" - también llamada"generación de los proscriptos", entre cuyos integrantes se encuentra el propio Sarmiento- se ve obligada a emigrar masivamente a Uruguay, Chile, Bolivia o Brasil. Civilización y barbarie. Vida de Juan Facundo Quiroga, folletín publicado en El Progreso de Santiago de Chile, constituye una de las obras antirrosistas más prominentes del período. Argirópolis, escrito dos años antes de la caída de Rosas, retoma muchos de los tópicos presentes en Facundo y formula una serie de propuestas políticas destinadas a orientar la gestión de las futuras autoridades: "El presente opúsculo ha sido escrito con la mente de sugerir, por el estudio de los antecedentes de la lucha, la geografía del país, y las instituciones argentinas, un medio de pacificación que a la vez ponga término a los males presentes, y cieguen en su fuente la causa de nuevas complicaciones, dejando definitivamnte constituidos aquellos países" (Argirópolis). En el interior de ese proyecto, la creación de una ciudad capital en la isla de Martín García (instrumento destinado a contener la voracidad porteña, redistribuir recursos económicos y simultaneamente captar la simpatía de las provincias del litoral argentino, lideradas por Urquiza) desempeña un papel importantísimo.

${ }^{2}$ Monte o colina de la Favela: topónimo; uno de los varios cerros que rodeaba a la localidad fundada por el líder milenarista Antonio Consejero en el norte del Brasil a fines del XIX. La denominación procede de un arbusto típico de la región y al parecer abundante en ese monte, la favela. Mutatis mutandi la palabra pasa a designar en este siglo los numerosos asentamientos de sectores pobres y marginalizados surgidos en las grandes ciudades del país como producto de migraciones internas ocurridas en diversos períodos. Esta nueva significación aparece inicialmente en Río de Janeiro donde las mayoría de las favelas, en especial las más antiguas, se sitúan de hecho en los morros (colinas o montes) enclavados en plena ciudad. Desconozco si el segundo sentido deriva del primero y hasta la fecha no he encontrado estudios relativos a esta cuestión. En todo caso, fue a partir de esta 'coincidencia' lingüística que surgieron algunas de las ideas aquí desarrolladas. 
locus que introduce una triple cesura con relación a la naturaleza: con relación a la naturaleza "en sí", a la naturaleza "de sí", de cada uno, a la naturaleza del "otro". Obviamente en los tres casos se trata de una naturaleza proyectada, construida como tal y expelida hacia afuera. Hacia adentro, en el interior de la superficie delimitada, los signos de lo profuso; una profusión dada a leer bajo una multiplicidad de formas: hombres, casas, edificios, comercios, talleres, calles, objetos, utensilios, ropas, riquezas. Todo eso se encuentra en la ciudad “... que es la que desarrolla la capacidad industrial del hombre y le permite extender sus adquisiciones" (Sarmiento 30). Todo eso reunido, reconcentrado en un estrecho espacio de territorio, ya que para Sarmiento cohesión y profusión son dos caras de la misma moneda. Así, a la cesura que establece el límite sucede la oposición que instituye el contraste entre lo populoso, numeroso, compacto, denso, lleno y pleno, por una parte, y lo desierto o seini, disperso, desparramado, escaso, deficiente e insuficiente, por otra. En el recinto de la ciudad, una abundancia contranatura que dice en la estructura de las cosas (y en la proximidad entre las cosas como parte de la estructura) la civilización/humanidad de unos. Afuera, extramuros, poco que cuente para la civilización: leguas y leguas de campo no surcado, cabezas de ganado por doquier, algún rancho perdido; en otras palabras, poco de lo que vale o cuenta y exceso de lo peor, de una naturaleza "no tratada".

Densidad (grados de concentración), artificio (grados de alejamiento con relación a una materialidad o una función supuestamente primera y por lo tanto "primitiva"): criterios que organizan una red básica de sentido, que redistribuyen y ordenan colecciones de palabras en la ciudad, en el campo o en las zonas intermediarias (Sarmiento 28). ${ }^{3}$

La distinción reaparece y se acentúa en Argirópolis donde la estrechez del territorio insular, sus reducidas dimensiones, cobran el estatuto de propriedad benéfica precisamente por favorecer lo concentrado (también lo "vertical", otro signo de la urbe que se contrapone a lo "bajo" y "chato" de las construcciones pampeanas). ¿Qué mejor, en efecto, que una pequeña isla para frenar la propensión al "desparramo" de las ciudades de la América española? ¿Qué mejor que una pequeña isla para impedir la permanente intrusión de lo rural/ natural que sepulta y destruye a las ciudades del interior? (Argirópoplis 134-6). ${ }^{4}$

Poca extensión, poca tierra y mucha piedra; otra ventaja considerable a los ojos de Sarmiento que así como opone vertical/horizontal, en el orden de las formas, opone durodurable — en este caso el "granito"-, a precario-perecible — barro, adobe, paja-, en el orden de los materiales (Argirópolis 138).

Completando el cuadro de características favorables están, por último, las posibilidades entrevistas en el agua: básicamente dos, complementarias y antitéticas. En efecto, en

\footnotetext{
${ }^{3}$ Véase a título de ilustración las descripciones hechas por Sarmiento de las "colonias alemana y escocesa del sur de Buenos Aires" y de las "villas nacionales del interior" respectivamente.

4 “ ¿No se presta la superficie de Martín García a contener una ciudad? ¡Cómo! (...) La América española se distingue por la superficie desmesurada que ocupan sus ciudades; y el hábito de ver diseminarse los edificios de un solo piso en las llanuras, nos predispone a hallar estrecho el espacio en que en Europa están reunidos doscientos mil habitantes. De este despilfarro del terreno viene que ninguna ciudad española en América pueda ser iluminada por el gas ni servida de agua, porque el costo excesivo de los caños que deben distribuir una u otra no encuentran cincuenta habitantes en una cuadra (...) Nuestro juicio no está habituado a la repentina aparición de ciudades. Estamos habituados a verlas morir más bien de inacción".
} 
una direción, el medio que circunda o rodea a Argirópolis aleja, separa, insta al corte con las prácticas imperantes en la América del Sur. En la otra dirección, en dirección a Europa o a América del Norte, el agua acerca, comunica, fomenta y acelera la circulación de bienes y de hombres a través de navíos y buques, embarcaciones que constituyen el reverso positivo de la carreta de bueyes - ya que también en lo que respecta a los modos, medios de transportes y hábitos que engendran, rige la bipolaridad que valoriza, por un lado, la "buena errancia", el nomadismo célere e industrioso del marinero-comerciante, mientras que desestima, por otro lado, "la escuadra de bajeles (carretas) que atraviesa pesadamente el desierto" (Sarmiento 36). En suma, en una dirección el agua sirve de barrera contra la realidad circundante tal como ocurre en las utopias clásicas; mientras que en la otra, sirve de nexo, estrecha vínculos. ${ }^{5}$ Pequeño paraíso artificial llamado a subvertir "el género de vida practicado en el continente": eso será Argirópolis y, para ello, nada mejor que una isla:

\begin{abstract}
Volviendo a las ventajas que aseguraría a los Estados del Plata la creación en aquella isla de una ciudad capital, apuntaremos una que para nosotros al menos es de una trascendencia incalculable. Tal es la influencia que ejercería sobre los hábitos nacionales esta sociedad echada en el agua si es posible decirlo, y rodeada necesariamente de todos los medios de poder que da la civilización. A nadie se ocultan los defectos que nos ha inoculado el género de vida llevado en el continente, el rancho, el caballo, el ganado, la falta de utensilios, como la facilidad de suplirlos por medios atrasados. ¿Qué cambio en las ideas y en las costumbres! ¡Si en lugar de caballos fuesen necesarios botes para pasearse los jóvenes; si en vez de domar potros, el pueblo tuviese allí que someter con el remo las olas alborotadas; si en lugar de paja y tierra para improvisarse una cabaña, se viese obligado a cortar a escuadra el granito! (Argirópolis 29).
\end{abstract}

\title{
II. LAS FORMAS DE LA POLIS: DUPLICACIONES DEL PAISAJE CIUDADANO
}

Por muy preciados e indispensables que sean ni "edificios de granito cortado a escuadra", ni "botes", ni “paredes pintadas", ni “lozas relucientes", ni “"muebles completos", ni "fracs", ni "corbatas" son suficientes para que se tenga una ciudad. La colección de objetos que funciona en el discurso sarmientino como unidad de medida de lo urbano no bastan sin embargo para definirla. Agente multiplicador y formador insustituible, la ciudad sarmientina es, sobre todo, lugar-origen de un determinado orden social, heredera de la polis, de la civitas romana, ciudad-Estado, ciudad-ley. Así, a la figura de la ciudad como usina productora de "buenos" objetos y de "buenos" hábitos en profusión se yuxtapone la figura de la ciudad como usina político-jurídico-administrativa, también ella una especie de paraíso artificial resultante de una serie de cortes, sujeciones, ablaciones o cercenamientos operados en la "naturaleza de cada uno". De modo que, coexistiendo con el paisaje material de la ciudad hay un paisaje institucional y, es obvio que igualmente en este plano (o sobre todo en él) Argirópolis representa la formulación del modelo en estado de pureza casi

\footnotetext{
${ }^{5}$ Aunque adoptando otra perspectiva de análisis, la presencia de este doble rasgo como componente diferencial de los discursos utópicos producidos por los proscriptos argentinos del XIX fue señalada por María Cecilia Graña en "La utopía como analogon: Sarmiento y el proyecto de una ciudad moderna”. Cuadernos Hispanoamericanos. Los Complementarios, 3 (1989).
} 
absoluta. Inventada para desempeñar el papel de máquina de Estado, la capital nonata debería albergar en su seno desde el principio

El congreso, el presidente de la Unión, el tribunal supremo de justicia, una sede arzobispal, el Departamento Topográfico, la administración de los vapores, la escuela náutica, la universidad, una escuela politécnica, otra de artes y oficios y otra normal para maestros de escuela, $y$ mil otros establecimientos administrativos y preparativos que supone la capital de un Estado civilizado (Argirópolis 31).

De hecho, aunque en otra clave, este paisaje reedita nuevamente las figuras/íconos del paisaje anterior, las convoca una por una desplazando su sentido hacia la órbita políticogubernamental. Así, los signos de lo populoso, lo lleno, lo concentrado, lo compacto reaparecen ahora sea bajo la forma de lo "numeroso en sí", sea bajo la forma de instancias colegiadas, organismos que constituyen a su vez expresiones o modulaciones de lo "intermediado": "representativas", esas instituciones suponen precisamente una delegación del poder-fuerza individual con vistas a la elaboración de un orden colectivo. La ficción del contrato que hace nacer y legitima semejante tipo de autoridad confisca esa cuota de poder ofreciendo como contrapartida una serie de obligaciones-derechos sancionados por la Ley, también ella una construcción recta, sólida, duradera y estable, como las piedras cortadas a escuadra en que se apoya la estructura arquitectónica de Argirópolis.

Contrastando con este paisaje institucional, el de la campaña pastora, espacio donde "La sociedad ha desaparecido completamente; sólo resta la familia feudal, aislada, y no habiendo sociedad reunida, toda clase de gobierno se hace imposible ..." (Sarmiento 60). Dispersas en un medio cuyo rasgo dominante es la dispersión, las instituciones del Estado no consiguen llegar hasta la campaña, se extravían mal se ponen a andar, desaparecen engullidas por el vacío que las rodea. O, lo que quizás sea peor aún para Sarmiento, si sobreviven pierden su forma ciudadana, se transforman (se deforman) en otra cosa - la mayoría de las veces, en el reverso exacto de lo que "deberían" ser; en una palabra, se ruralizan. ¿La administración de la justicia en el campo? Una variante del caudillismo practicado por el "capataz de carretas" (Sarmiento 144). "Arbitraria", "ejecutiva", "sin formas", la autoridad en el campo desconoce todo tipo de mediación. Ningún protocolo jurídico ni régimen de penas codificado que se interponga entre el representante del poder -que en este caso se confunde con el poder mismo-y los sujetos sobre los cuales ese poder se ejerce. Ningún supuesto universal en el plano de las obligaciones, derechos y garantías que haga las veces de fundamento (recordemos no obstante que es la ciudad la que crea legalidades diferenciadas y francamente lesivas para el hombre de campo como, por ejemplo, la ley de levas). Para Sarmiento, traspuestas las fronteras de la polis, las instituciones se mimetizan con la sociedad pastora, se tornan seminómades como los individuos que la integran, inestables, frágiles y precarias como las moradas que habitan; son construcciones de paja y barro, no de piedra dura, geométrica e "idénticamente" cortada.

En Argirópolis y en Facundo los constituyentes del paisaje político-institucional y los del paisaje "sin más" hablan el mismo idioma o por lo menos usan el mismo léxico de base, se espejan entre sí y repelen a su "otro". Por una parte, enunciadas en dos registros, las palabras-soportes de la ciudad; por otra, también en dos registros especulares, las del campo. 


\section{Desplazamientos}

Como para Sarmiento, para Euclides da Cunha los rasgos del paisaje "estereografan" u "objetivan" la estructura de un paisaje-sociedad, muestran su ser en la calidad, cantidad y textura de los elementos matriciales que lo componen, en su disposición, en las reglas que organizan la combinatoria de esos signos. Como para Sarmiento, para Euclides da Cunha cada paisaje-sociedad dice su ser en dos planos. Sin embargo, a pesar de las coincidencias generales ni la clasificación, ni la axiología de los paisajes ni, menos aún, la gramática que rige la combinatoria de los signos en el interior de cada uno de ellos, permanecen incólumes. De cierta forma, podría afirmarse que en Los Sertones los signos (sarmientinos) "enloquecen", que producen una gramática "aberrante" perturbando con ello la clasificación, número y estatuto de los paisajes representados. En primer lugar, la ciudad/paradigma (la ciudad como dispositivo acelerador del proceso civilizatorio) ha desaparecido en Los Sertones. Las poquísimas referencias a la capital carioca insisten en el establecimiento de un analogon precisamente con aquello que, por principio, debería funcionar como contrafigura. En Los Sertones, "la calle del Ouvidor vale por un desvío de las caatingas", la multitud de Río de Janeiro "... arroja objetos, libros, papeles, muebles y utensilios" a la calle para hacer "una fogata" (373) -dicho de otro modo, destruye aquello que para Sarmiento la ciudad acumula y por lo cual es valiosa-; en Los Sertones, las instituciones republicanas de la capital actúan de manera no menos impulsiva y primitiva que sus supuestos oponentes (377). Se diría que en el discurso de este escritor no hay restos de un pensamiento utópico indisolublemente vinculado a la urbe y que, en consecuencia, la bipolaridad que anima al modelo sarmientino se queda sin uno de sus pilares, el fundamental. Con todo, es necesario advertir que la pérdida de ese punto de apoyo no redunda en ninguna clase de equilibrio ulterior por compensación o transferencia de lo perdido hacia otra área. La deflación de lo urbano no genera automáticamente una inflación correlativa y paralela de lo rural, que reestablecería el orden sólo que con los signos invertidos. La parte que se arruina o se tulle en uno de los polos del modelo no se recupera ni se repone en el contrario, al menos no 'sin más o no simétricamente. Porque, por otro lado - esto es, por el lado del otro paisaje, el ruralirrumpen a su turno combinaciones impensadas, anómalas, "monstruosas"; prefiguraciones de un paisaje en el que los signos se salen de su curso "natural", se "contaminan", se mezclan. Una visión/versión del "campo" (¿pero es posible continuar llamándolo así?) que desestabiliza el esquema sarmientino, que lo lleva al colapso.

\section{EXCURSIONES}

La primera descripción sumaria de Canudos parte del aspecto geográfico y se organiza, como es habitual, por aproximaciones sucesivas: inicialmente se nos hace ver el "suelo revuelto" de la zona adyacente para luego "trepar hasta la cumbre del monte de la Favela". Allí, desde lo alto, una especie de mirador "permite abarcar de una ojeada el conjunto del terreno" y pone al "viandante" frente a la "antítesis de lo que viera": "... y casi se entendía que los campesinos crédulos ... creyesen que ahi era el cielo" (da Cunha 108). ${ }^{6}$ Alrededor

\footnotetext{
${ }^{6}$ La traducción de los pasajes citados es mía.
} 
de ese cielo, una "elipsis majestuosa de montañas". O como se dirá más adelante, "una cintura de sierras con las que el buen Jesús aislara del resto del mundo esa Canaán sagrada" (da Cunha 235). Semejante a la cintura de agua que rodea a Argirópolis (semejante a "una" de las funciones que asume en el libro), montañas y suelo estéril sirven para instituir el corte. A semejanza de lo que se sueña para Argirópolis, a partir del "cielo", desde lo alto, la visión, abajo, de lo lleno, lo compacto, lo numeroso. Pero como ocurre al "trepar la cumbre del monte de la Favela", la semejanza súbitamente se resuelve en "antítesis":

Aprisionada en una de esas vueltas se divisaba una depresión mayor, circundada de colinas ... Y abarrotándola, colmándola toda de confusos techos incontables, un enorme acerbo de ranchos ... (da Cunha 118).

En la superficie estrecha, "colmándola", "un enorme acerbo de ranchos": una numerosidad en el corazón del desierto que jamás imaginó el autor de Facundo, una primera manifestación de desacato a cierta lógica distributiva de los signos en el espacio territorial.

En el índice de la segunda parte de Los Sertones se lee: "Canudos- antecedentes aspecto original-y crecimiento vertiginoso. Régimen de la urbs" (da Cunha 140). El relato de ese proceso comienza por la prehistoria de Canudos, pasado del espacio en el que se recuerda la "hacienda floreciente" de décadas anteriores, el "aldeamiento" sospechoso que medra a su alrededor, la decadencia final, especie de vacío que servirá de marco a la historia que interesa (da Cunha 231).

Súbitamente ese paisaje-memoria-protohistoria donde se yuxtaponen los signos de lo "rural/señorial" (prácticamente ausentes en los textos sarmientinos) y de lo "rural-popularmarginal-peligroso" (éstos sí, una presencia constante), súbitamente ese paisaje se "transmuta":

Data de aquel año su revivescencia y crecimiento rápido. El aldeamiento efímero de los campesinos vagos, ... iba a transmutarse, ampliándose en poco tiempo, en la Troya de adobe de los yagunzos (da Cunha 231).

Expandiendo el enunciado sintético, la representación de ese pasaje abrupto. En una primera instancia, la recapitulación de las migraciones registadas en el sertón hacia 1893, migraciones que "parten de todos los puntos" dejando quintas y villas "deshabitadas" para convergir en una estrecha planicie; trasvasamiento de hombres que, por un lado, vacía las pequeñas comunidades pero, por el otro, las reagrupa en una entidad mayor modificando con ello su estructura/naturaleza primordial. Desde ese punto de vista, podría afirmarse que el principio que rige el movimiento de Facundo en el "presente", bajo el dominio de Rosas, es el de la dispersión, una dispersión que obviamente Sarmiento abomina. Porque para él, en el suelo argentino, "la ignorancia y la pobreza" consustanciales al mundo rural “... están como las aves de rapiña esperando que las ciudades del interior den su último suspiro, para devorar su presa, para hacerlas campo, estancia" (Sarmiento 74). En Los Sertones, la dispersión/vaciamiento primero, se torna inmediatamente impulso concentracional: "Los grupos se adunaban por los caminos, para arribar al fin, juntos, a Canudos" (da Cunha 232). Lo poco numeroso se pierde o se deshace para dar lugar a la reunión de los muchos hombres 
y las muchas casas: "La aldea crece vertiginosamente, desbordando las colinas" (da Cunha 232), de cierto modo se transforma en ciudad. ¿Pero en qué tipo de ciudad? No, por cierto, en una ciudad semejante a la Argirópolis de los devaneos sarmientinos. En la visión/versión de Euclides da Cunha, Canudos es "urbs monstruosa", "civitas siniestra del error", "ciudad salvaje", oxímorons que resumen la tensión suscitada por signos prohibidos de encontrarse pero que ahora, sin embargo, se conjugan. Porque en Canudos, lo lleno, lo poblado, lo numeroso se combina con lo "primitivo", lo "elemental", lo "irregular", lo "rústico". En principio, se diría que esa combinación es impensable e imposible para el escritor sanjuanino; en principio, las expresiones oximorónicas condensan ese imposible tornado realidad que perturba el modelo y, obviamente, ante todo, al propio Euclides da Cunha.

Volvamos al momento en el que se registra el crecimiento vertiginoso de Canudos:

La aldea crecía vertiginosamente desbordando las colinas. La edificación rústica permitía a la multitud sin lares hacer hasta quince casas por día (...) Aquello se hacía al acaso, enloquecidamente.

Laurbs monstruosa, de barro, definía bien la civitas siniestra del error. El pueblo nuevo surgía, en algunas semanas, ya transformado en ruinas. Nacía viejo. (...)

No se distinguian las calles. Las sustituía un dédalo desesperante de rincones estrechísimos, que separaban mal el desorden caótico de los ranchos hechos al acaso ... como si todo aquello hubiese sido construido febrilmente, en una noche, por una multitud de locos ... (da Cunha 232-233).

Desenvolvimiento rapidísimo pero "rústico" y, porque rústico, compacto pero "caótico", sin orden ni dirección legible (no con el orden que se desearía encontrar), "un dédalo desesperante de rincones estrechísimos", "un desorden caótico de ranchos"; desenvolvimiento "contranatura", deformidad o deformación de lo que mal habiendo nacido ya tiene el aspecto de lo viejo, ruina precoz. Con esas "paradojas" el discurso euclidiano busca apreender y dar a ver una primera panorámica de Canudos. Con esas paradojas y su reconversión al lenguaje de la enfermedad, de la locura colectiva. O con la multiplicación "enloquecida" de los nombres para nombrar lo inaudito pues, en tan sólo dos páginas y no mucho más de veinte años Canudos transita por las siguientes denominaciones/condiciones: "hacienda de ganado", "tapera", "aldeamiento efímero de campesinos vagos", "Troya de adobe", "urbs monstruosa" "civitas siniestra del error", "tapera colosal", "ciudad cuyo suelo hubiese sido brutalmente doblado por un terremoto". "Rural" por origen ("antigua hacienda de ganado" pero también punto de convergencia de una población eminentemente rural ou semirural); "urbana" por densidad y número de habitantes y moradas. "Urbana" pero de nuevo, otra vez, al acercarse/describir la estructura de cada una de esas viviendas, retorno a la materialidad rural, al "adobe", a los "gajos de icó", a los "compartimientos minúsculos" y casi desprovistos de objetos. Porque a la primera infracción al modelo sarmientino (a la combinación de lo mucho, lleno, denso y numeroso con lo "rústico") sigue la reposición del modelo (ya arruinado) en el detallamiento descriptivo de las unidades constituyentes. Mirada de lejos, las muchas y "desordenadas" viviendas; mirada de cerca y por dentro, los "trastes groseros y escasos". Ninguna proliferación de lo primoroso y ornado que nos recuerde la villa de inmigrantes escoceses descripta por Sarmiento. Aquí, cada una de los millares de casas vuelve a decir la "mengua" (da Cunha 233). 
Al reexaminar la disposición general de Canudos, Euclides da Cunha subraya la presencia de "construcciones livianas distantes del núcleo compacto del caserío", que "... parecían obedecer al trazado de un plan de defensa". Inicialmente "apiñados" en la depresión donde se erigía la antigua iglesia, los "ranchos" rebasan rápidamente ese límite primero y comienzan a "desparramarse" por los cerros circunvecinos formando "líneas irregulares de baluartes" (da Cunha 235). Así, la descripción del trazado urbanístico se transforma inmediatamente en un informe sobre las condiciones estratégicas de la "ciudad salvaje", mapa de un territorio donde "cada lar" es al mismo tiempo "un reducto":

Porque la ciudad salvaje, desde el principio, tenía en torno, acompañándola en su crecimiento rápido, un círculo formidable de trincheras cavadas en todas las direcciones ... Veladas por matorrales inextricables de macambiras no se advertían a la distancia. Viniendo de levante el viajero que las bordease, al divisar, dispersos sobre los cerros los ranchos exiguos a la manera de garitas, creería topar con un rancherío disperso de vaqueros inofensivos. Alcanzaba, de repente, el caserío compacto, sorprendido, como si cayese en una emboscada (da Cunha 352-353).

Menos que el círculo oculto de "formidables trincheras" y su eventual veracidad o falsedad histórica, lo verdaderamente interesante en este fragmento reside en las impresiones del "viajero" que a ellas se aproximase viniendo del levante. Porque, de seguir ese rumbo, el hipotético viajero-observador "... al divisar, dispersos sobre los cerros, los ranchos exiguos a la manera de garitas, creería topar con un rancherio disperso de vaqueros inofensivos". De hecho, no me parece imposible que la razón de ser de ese espejismo benévolo y fugaz deba ser buscada en la insistencia recurrente de un vocablo, en el retorno de lo disperso (lo poco, lo separado) como condición sine qua non de una visión positiva. Dispersos, casas y hombres pierden los signos negativos que los cercaban en las descripciones anteriores, de cierto modo "se desarman", se tornan "rancherío de vaqueros inofensivos", comunidad exigua, pequeño grupo rural-tradicional pasible de retratos idealizados como los que proliferan en la segunda parte de Los Sertones (ahí donde el autor nos muestra lo cotidiano, trabajos, fiestas, hábitos y costumbres del vaquero-sertanero "bravo", "honestísimo", "inquebrantable"). Es cierto que esos retratos nunca llegan a alcanzar el nivel de la idealización absoluta, que la contradicción o el desdecirse permanentes son una regla del discurso euclidiano pero la tendencia a exaltar las virtudes de $E l$ Hombre, cuando se lo declina en singular o en un plural 'contenido', me parecen bastante claras. Reunido, al contrario, "el rancherío compacto" se transforma súbitamente en "emboscada":

Canudos, entretejido de rincones de menos de dos metros de ancho ... tenía la ilusoria fragilidad de los muros de adobe que la formaban. Era peor que una ciudadela inscrita en polígonos o blindada de casamatas espesas. Ampliamente abierta a los agresores que podían abatir a mano las paredes y techos de barro o traspasarlas por todos lados, tenía la inconsistencia y la flexibilidad traicionera de una red desmesurada. (...). El hábito de la caza de los yagunzos les inspiró, tal vez, la creación sorprendente de la "ciudadela-trampa" ... (da Cunha 352-353). 
Ciudadela-trampa que extrae fuerzas de su fragilidad, que amenaza desmoronarse y arrastrar al enemigo en su caída, peligrosidad de lo "fragilísimo": en el desierto de Los Sertones, la antevisión de las favelas por venir. O, mejor aún, de las visiones/versiones más frecuentes que las cercan. Pesadilla del modelo sarmientino; "grey revoltosa" - y mucha.

BIBLIOGRAFIA

Argirópolis (1850). Buenos Aires: La Cultura Argentina, 1916.

da Cunha, Euclides. Os Sertões (1902). Edición crítica organizada por Walnice Nogueira Galvão. San Pablo: Brasiliense, 1985.

Sarmiento, Domingo Faustino. Facundo o civilización y barbarie en las pampas argentinas (1845). Caracas: Editora Ayacucho, 1977. 